\title{
PENGEMBANGAN MEDIA ZLIQUBO UNTUK MENINGKATKAN KECERDASAN VISUAL SPASIAL ANAK TK
}

\author{
Dita Primashanti Koesmadi \\ STKIP Modern Ngawi \\ Email: dita.prima23@gmail.com \\ Arwendis Wijayanti \\ STKIP Modern Ngawi \\ Email: arwendiswijayanti@gmail.com \\ Elisa Rahayu \\ STKIP Modern Ngawi \\ Email: elisarahayu@gmail.com
}

\begin{abstract}
Development of Zliqubo Media (Quiet Book Puzzle) to Improve Visual Spatial Intelligence of Group B Kindergarten Children in Kwadungan District, Ngawi Regency. This study aims to: 1) Describe the effectiveness of Zliqubo (Puzzle Quiet Book) to improve the visual spatial intelligence of kindergarten children in group $B$ in Kwadungan District, Ngawi Regency. 2) Describe the efficiency of Zliqubo (Quiet Book Puzzle) to improve the spatial visual intelligence of Group B Kindergarten children in Kwadungan District, Ngawi Regency. 3) Describe the attractiveness of Zliqubo (Puzzle Quiet Book) to improve the visual spatial intelligence of Group B Kindergarten children in Kwadungan District, Ngawi Regency. The research used was Borg \& Gall Research and Development. The steps taken include analysis of potential and problems, data collection, product design, product validation, design revisions, product trials, product revisions. The product was tested on students through two stages of validation testing, namely a small group trial of 5 children and a large group trial of 15 children. The subject of the trial was the children of group B Kindergarten Dharma Wanita Dinden which consisted of a small group trial of 5 students and a large group trial of 13 students. Product viability is based on the results of the assessment of material experts, media experts and learning design experts. Data collection techniques using observation, interviews, and documentation. Data analysis in the form of quantitative descriptive. The results showed that the Zliqubo (Puzzle Quiet Book) which had been developed through a series of trials and expert validation was declared feasible. This is supported by expert material assessment with an average score of 3.42 included in the feasible category, assessment of experts with an average score of 3.7 including the feasible category, learning design expert assessment with an average score of 3.3 including eligible category. product trials get a percentage score (1) $100 \%$ of children can do activity I; (2) $93.75 \%$ of children can do activity II; (3) $87.5 \%$ of children can do activity III; (4) $89.7 \%$ of children easily carry out activities; (5) $94.86 \%$ of children are safe in playing activities with Zliqubo (Quiet Book Puzzle); (6) 92.30\% of children feel happy when playing with Zliqubo (Puzzle Quiet Book). Based on the results of the research that has been done, it can be concluded that the Zliqubo (Puzzle Quiet Book) for the learning of Group B Kindergarten students in Kwadungan Subdistrict, Ngawi Regency is feasible to use.
\end{abstract}

Key words: Zliqubo (Quiet Book Puzzle), Visual spatial intelligence, Kindergarten 
Dita Primahasti dkk, Pengembangan media Zliqubo untuk meningkatkan kecerdasan visual spasial anak TK

\begin{abstract}
Abstrak: Pengembangan Media Zliqubo (Puzzle Quiet Book) untuk Meningkatkan Kecerdasan Visual Spasial Anak Taman Kanak-kanak Kelompok B di Kecamatan Kwadungan Kabupaten Ngawi. Latar belakang dalam penelitian ini adalah masih kurangnya kemampuan visual spasial pada anak Taman Kanak-kanak Kelompok B di TK Dinden. Penelitian ini bertujuan untuk: 1) Mendeskripsikan kefektifan media Zliqubo (Puzzle Quiet Book) untuk meningkatkan kecerdasan visual spasial anak Taman Kanakkanak kelompok B di Kecamatan Kwadungan Kabupaten Ngawi. 2) Mendeskripsikan kefisienan media Zliqubo (Puzzle Quiet Book) untuk meningkatkan kecerdasan visual spasial anak Taman Kanak-kanak kelompok B di Kecamatan Kwadungan Kabupaten Ngawi. 3) Mendeskripsikan kemenarikan media Zliqubo (Puzzle Quiet Book) untuk meningkatkan kecerdasan visual spasial anak Taman Kanak-kanak kelompok B di Kecamatan Kwadungan Kabupaten Ngawi.Penelitian yang digunakan adalah penelitian pengembangan (Research and Development) Borg \& Gall. Langkah yang ditempuh meliputi analisis potensi dan masalah, pengumpulan data, desain produk, validasi produk, revisi desain, uji coba produk, revisi produk. Produk diuji coba kepada anak didik melalui dua tahap uji validasi yaitu uji coba kelompok kecil kepada 5 anak dan uji coba kelompok besar kepada 15 anak. Subjek uji coba adalah anak kelompok B TK Dharma Wanita Dinden yang terdiri dari uji coba kelompok kecil 5 siswa dan uji coba kelompok besar 13 siswa. Kelayakan produk didasarkan pada hasil penilaian ahli materi, ahli media dan ahli desain pembelajaran. Teknik pengumpulan data menggunakan observasi, wawancara, dan dokumentasi. Analisis data berupa deskriptif kuantitatif. Hasil penelitian menunjukkan bahwa media Zliqubo (Puzzle Quiet Book) yang telah dikembangkan melalui serangkaian uji coba serta validasi ahli dinyatakan layak. Hal ini didukung oleh penilaian ahli materi dengan rata-rata skor 3,42 termasuk dalam kategori layak, penilaian ahli media dengan rata-rata skor 3,7 termasuk kategori layak, penilaian ahli desain pembelajaran dengan rata-rata-rata skor 3,3 termasuk kategori layak. uji coba produk mendapatkan presentase skor (1) 100\% anak dapat melakukan kegiatan I; (2) 93,75\% anak dapat melakukan kegiatan II; (3) $87,5 \%$ anak dapat melakukan kegiatan III; (4) $89,7 \%$ anak mudah melakukan kegiatan; (5) $94,86 \%$ anak aman dalam melakukan kegiatan bermain dengan media Zliqubo (Puzzle Quiet Book); (6) 92,30\% anak merasa senang saat bermain dengan media Zliqubo (Puzzle Quiet Book). Berdasarkan hasil penelitian yang telah dilakukan dapat disimpulkan bahwa media Zliqubo (Puzzle Quiet Book) untuk pembelajaran anak didik Taman Kanak-kanak Kelompok B di Kecamatan Kwadungan Kabupaten Ngawi layak digunakan.
\end{abstract}

Kata Kunci : Media Zliqubo (Puzzle Quiet Book), Kecerdasan Visual spasial, Kelompok B Taman Kanak-kanak.

\title{
PENDAHULUAN
}

Pendidikan anak usia dini merupakan suatu usaha secara sadar serta terencana yang dilakukan kepada anak yang usianya 0-6 tahun dengan pemberian rangsangan pendidikan untuk membantu setiap tumbuh kembangnya baik jasmani maupun rohani, serta mempersiapkan kesiapan mereka untuk menempuh pendidikan lebih lanjut. Hal ini tercantum dalam Peraturan Menteri Pendidikan dan Kebudayaan Republik Indonesia Nomor 146 Tahun 2013 Pasal 1 menyatakan bahwa Pendidikan Anak Usia Dini (PAUD) merupakan suatu upaya pembinaan yang 
diperuntukan bagi anak yang baru lahir sampai berusia enam tahun dan dilakukan melalui pemberian stimulasi untuk membantu pertumbuhan dan perkembangan jasmani dan rohani agar anak mempunyai kesiapan mengikuti jenjang pendidikan selanjutnya. Anak usia dini menurut NAEYC (National Association Education for Young Children) merupakan anak yang berada pada rentang usia 0-8 tahun".

Pembelajaran di Taman Kanak-kanak menerapkan pendekatan pembelajaran belajar melalui bermain. Tujuan Taman Kanak-kanak untuk meletakkan dasar ke arah perkembangan sikap, ilmu pengetahuan, ketrampilan, kreativitas (daya cipta) dan kecerdasan majemuk (multiple intelligences) yang diperlukan oleh anak didik dalam menyesuaikan diri dengan lingkungan. Kecerdasan menurut paradigma multiple intelligences diidentifikasikan sebagai kemampuan yang mempunyai tiga komponen utama, yakni: (1) kemampuan untuk menyelesaikan masalah yang terjadi dalam kehidupan sehari-hari, (2) kemampuan untuk menghasilkan persoalan-persoalan baru yang dihadapi untuk diselesaikan, dan (3) kemampuan untuk menciptakan sesuatu atau menawarkan jasa yang akan menimbulkan penghargaan dalam budaya seseorang. ${ }^{2}$ Oleh karena itu sangatlah penting sekali seorang guru PAUD untuk memahami dan mengoptimalkan setiap aspek perkembangan dan kecerdasan anak agar kecerdasan anak berkembang secara optimal.

Kecerdasan visual spasial adalah kemampuan untuk membentuk suatu gambaran tentang tata ruang di dalam pikiran, anak kaya khayalan internal (internal imagery) sehingga cenderung imajinatif dan kreatif. Anakanak dengan kecerdasan visual-spasial yang tinggi cenderung berpikir dengan berimajinasi, berpikir dengan gambar dan imej (image). Biasanya mereka menyukai kegiatan bermain Puzzle, menggambar, bermain balok, bermain maze, membangun bentuk, serta berimajinasi membentuk

1 Sofia Hartati. 2005. Perkembangan Belajar Pada Anak Usia Dini. Jakarta: Departemen Pendidikan Nasional, h. 8

${ }^{2}$ Busthomi. 2012. Panduan Lengkap PAUD Melejitkan Potensi dan Kecerdaan Anak Usia Dini.Jakarta : Citra Publishing. H. 78 
Dita Primahasti dkk, Pengembangan media Zliqubo untuk meningkatkan kecerdasan visual spasial anak TK

bangunan-bangunan lewat permainan ${ }^{3}$. Berdasarkan observasi awal pada anak kelompok B di TK Dharma Wanita Dinden Kecamatan Kwadungan Kabupaten Ngawi sebagai sampel penelitian ini, khususnya pada kecerdasan visual spasial diperoleh data : (1) jumlah anak kelompok B adalah 18 anak, yang terdiri dari 7 anak perempuan dan 11 anak laki-laki (2) untuk aspek perkembangan yang pertama, anak belum dapat memahami warna (3) memahami bentuk-bentuk geometri (4) dan memahami benda berdasarkan ukuran. Hal ini disebabkan oleh guru kurang kreatif dalam membuat media pembelajaran, guru jarang memberikan kegiatan yang dapat mengembangkan kecerdasan visual spasial anak. Setiap kegiatan guru memberikan contoh yang kurang menarik. Selain itu, guru sering memberikan tugas dalam lembar kerja anak (LKA) sehingga kecerdasan visual spasial menjadi kurang diperhatikan.

Salah satu cara yang dapat digunakan untuk meningkatkan kecerdasan visual spasial anak yaitu dengan penggunaan media pembelajaran yang tepat dan menarik dengan memanfaatkan media Zliqubo (Puzzle Quiet Book). Zliqubo (Puzzle Quiet Book) adalah sebuah media yang efektif untuk mengajarkan secara menarik warna, bentuk, ukuran, dan arah. Zliqubo terbuat dari kain flannel yang dibentuk menjadi sebuah buku dengan warna-warna cerah, berisi aktivitas permainan sederhana seperti belajar mengenal warna, mengenal bentuk-bentuk geometri, mengurutkan berdasarkan ukuran. Penggunaan Media Zliqubo (Puzzle Quiet Book) juga dapat digunakan untuk melatih daya ingat, daya nalar, kreativitas, dan menyusun penggalan-penggalan fakta menjadi suatu bentuk keseluruhan yang mempunyai arti dan selanjutnya akan membentuk suatu pengetahuan baru yang dapat diceritakan kepada orang lain berdasarkan pengalaman.

${ }^{3}$ Yuliani. 2012. Bermain Kreatif Berbasis Kecerdasan Majemuk. Jakarta: Indeks.,h. 20 
Berdasarkan uraian di atas, untuk mengembangkan media yang sesuai untuk kecerdasan visual spasial anak, maka akan dilakukan penelitian dan pengembangan dengan judul "Pengembangan Media Zliqubo (Puzzle Quiet Book) untuk Meningkatkan Kecerdasan Visual Spasial Anak Taman Kanak-kanak Kelompok B di Kecamatan Kwadungan Kabupaten Ngawi".

\section{METODE PENELITIAN}

Penelitian yang digunakan adalah penelitian pengembangan (Research and Development). Langkah yang ditempuh meliputi analisis potensi dan masalah, pengumpulan data, desain produk, validasi produk, revisi desain, ujicoba produk, revisi produk. Produk diuji cobakan kepada anak didik melalui dua tahap uji validasi yaitu uji coba kelompok kecil kepada 5 anak dan uji coba kelompok besar kepada 13 anak. Subjek uji coba adalah anak kelompok B TK Dharma Wanita Dinden yang terdiri dari uji coba kelompok kecil 5 siswa dan uji coba kelompok besar 13 siswa. Kelayakan produk didasarkan pada hasil penilaian ahli materi, ahli media dan ahli desain pembelajaran. Teknik pengumpulan data menggunakan observasi, wawancara, dan dokumentasi. hasil observasi berupa hasil kecerdasan visual spasial anak, wawancara dilaksanakan oleh peneliti dengan guru untuk mengetahui kemampuan visual spasial anak, sedangkan dokumentasi berupa hasil kegiatan penelitian berupa foto dan video. Teknik analisis data yang digunakan adalah data kualitatif berupa saran dan masukan dari para ahli yang digunakan untuk melakukan revisi terhadap rancangan produk serta merupakan teknik analisis deskriptif dan data kuantitaif berupa presentase. 
Dita Primahasti dkk, Pengembangan media Zliqubo untuk meningkatkan kecerdasan visual spasial anak TK

\section{KERANGKA TEORI}

Anak usia dini menurut NAEYC (National Association Education for Young Children) merupakan anak yang berada pada rentang usia 0-8 tahun $^{4}$. Kecerdasan menurut paradigma multiple intelligences diidentifikasikan sebagai kemampuan visual spasial anak mempunyai tiga komponen utama, yakni: (1) kemampuan untuk menyelesaikan masalah yang terjadi dalam kehidupan sehari-hari, (2) kemampuan untuk menghasilkan persoalan-persoalan baru yang dihadapi untuk diselesaikan, dan (3) kemampuan untuk menciptakan sesuatu atau menawarkan jasa yang akan menimbulkan penghargaan dalam budaya seseorang ${ }^{5}$. Oleh karena itu sangatlah penting sekali seorang guru PAUD untuk memahami dan mengoptimalkan setiap aspek perkembangan dan kecerdasan anak agar kecerdasan anak berkembang secara optimal.

Kecerdasan visual spasial adalah kemampuan untuk membentuk suatu gambaran tentang tata ruang di dalam pikiran, anak kaya khayalan internal (internal imagery) sehingga cenderung imajinatif dan kreatif. Anakanak dengan kecerdasan visual-spasial yang tinggi cenderung berpikir dengan berimajinasi, berpikir dengan gambar dan imej (image). Biasanya mereka menyukai kegiatan bermain Puzzle, menggambar, bermain balok, bermain maze, membangun bentuk, serta berimajinasi membentuk bangunan-bangunan lewat permainan ${ }^{6}$.

\footnotetext{
${ }^{4}$ Sofia Hartati. 2005. Perkembangan Belajar Pada Anak Usia Dini. Jakarta: Departemen Pendidikan Nasional, h. 8

${ }^{5}$ Busthomi. 2012. Panduan Lengkap PAUD Melejitkan Potensi dan Kecerdaan Anak Usia Dini.Jakarta : Citra Publishing. H. 78

${ }^{6}$ Yuliani. 2012. Bermain Kreatif Berbasis Kecerdasan Majemuk. Jakarta: Indeks.,h. 20
} 


\section{TEMUAN DAN PEMBAHASAN}

\section{TEMUAN}

1. Analisis

Analisis dalam penelitian ini dilakukan pada analisis terhadap potensi dan masalah. Tahap awal dalam penelitian ini yaitu dengan dilakukannya observasi awal dengan wawancara kepada guru untuk menemukan potensi dan masalah .

2. Pengumpulan Data

Pengumpulan data berupa data analisis kebutuhan anak melalui wawancara dengan guru kelas dan kepala sekolah, menunjukkan bahwa anak membutuhkan media yang efektif untuk mengajarkan secara menarik warna, bentuk geometri, ukuran, arah.

3. Desain

Pada tahap desain diperoleh hasil bahwa desain produk ini mencakup isi bahan materi dengan langkah sebagai berikut:

a. Memilih tema berdasarkan acuan pada kurikulum

b. Merumuskan isi materi

c. Menyediakan alat dan bahan

d. Pengembangan produk

e. Validasi Ahli

Produk awal berupa Zliqubo (Puzzle Quiet Book) dilakukan validasi kepada ahli materi yaitu dosen pengampu Mata Kuliah Konsep Dasar Pendidikan Anak Usia Dini kemudian ahli media yaitu dosen pengampu Media Pembelajaran Anak Usia Dini dan Ahli Desain Pembelajaran yaitu dosen pengampu Metode Kreativitas Anak Usia 
Dita Primahasti dkk, Pengembangan media Zliqubo untuk meningkatkan kecerdasan visual spasial anak TK

Dini. Validasi ini dimaksudkan untuk mengetahui kelayakan Zliqubo (Puzzle Quiet Book) yang nantinya akan digunakan sebagai pedoman dalam revisi jika ditemukan kekurangan. Hasil penilaian diperoleh data sebagai berikut :

Tabel 1

Data Hasil Validasi Ahli Media

\begin{tabular}{|c|c|c|c|c|c|}
\hline No & Aspek & $\begin{array}{l}\sum \\
\text { Indi- } \\
\text { kator }\end{array}$ & $\begin{array}{c}\sum \\
\text { Ahli } \\
\text { Media }\end{array}$ & $\begin{array}{l}\text { Rata- } \\
\text { rata }\end{array}$ & kategori \\
\hline 1 & $\begin{array}{l}\text { Segi } \\
\text { Fisik }\end{array}$ & 4 & 14 & 3,5 & $\begin{array}{c}\text { Sangat } \\
\text { Baik }\end{array}$ \\
\hline 2 & $\begin{array}{l}\text { Segi } \\
\text { Pemanf } \\
\text { aatan }\end{array}$ & 2 & 8 & 4 & $\begin{array}{c}\text { Sangat } \\
\text { Baik }\end{array}$ \\
\hline 3 & $\begin{array}{l}\text { Segi } \\
\text { Warna }\end{array}$ & 3 & 12 & 4 & $\begin{array}{c}\text { Sangat } \\
\text { Baik }\end{array}$ \\
\hline 4 & $\begin{array}{l}\text { Segi } \\
\text { Gambar }\end{array}$ & 2 & 7 & 3,5 & $\begin{array}{c}\text { Sangat } \\
\text { Baik }\end{array}$ \\
\hline 5 & $\begin{array}{l}\text { Segi } \\
\text { Desain }\end{array}$ & 4 & 14 & 3,5 & $\begin{array}{c}\text { Sangat } \\
\text { Baik }\end{array}$ \\
\hline \multicolumn{4}{|c|}{ Skor rata-rata keseluruhan } & 3,7 & $\begin{array}{c}\text { Sangat } \\
\text { Baik }\end{array}$ \\
\hline
\end{tabular}

Berdasarkan hasil validasi media yang telah dipaparkan di table di atas, dijelaskan bahwa semua aspek penilaian dari validator mendapat nilai sangat baik sehingga media layak digunakan.

4. Uji coba

Setelah media Zliqubo (Puzzle Quiet Book) dinyatakan layak sebagai media pembelajaran, langkah selanjutnya yaitu uji coba produk. Produk diuji coba kepada anak didik melalui dua tahap uji coba yaitu uji coba kelompok kecil kepada 5 anak dan uji coba kelompok besar kepada 13 anak.

Hasil uji coba kelompok kecil yaitu anak-anak TK Dinden diperoleh dari pengisian pedoman observasi dan penilaian mengenai tingkat kemudahan, keamanan, menyenangkan dan aspek kecerdasan visual spasial. Adapun data yang telah diisi akan ditampilkan sebagai berikut: 
Tabel 2

Data Hasil Pedoman Penilaian Uji Kelompok Kecil

\begin{tabular}{|c|c|c|c|c|}
\hline No & Nama & Kegiatan 1 & Kegiatan 2 & Kegiatan 3 \\
\hline 1 & Sh & $100 \%$ & $75 \%$ & $75 \%$ \\
\hline 2 & $\mathrm{Nt}$ & $100 \%$ & $100 \%$ & $75 \%$ \\
\hline 3 & $\mathrm{Rg}$ & $100 \%$ & $75 \%$ & $100 \%$ \\
\hline 4 & Ad & $100 \%$ & $75 \%$ & $100 \%$ \\
\hline 5 & $\mathrm{KI}$ & $100 \%$ & $75 \%$ & $75 \%$ \\
\hline \multicolumn{2}{|c|}{ Rata-rata } & $100 \%$ & $80 \%$ & $85 \%$ \\
\hline
\end{tabular}

Hasil uji coba kelompok besar diperoleh dari pengisian pedoman observasi dan penilaian mengenai tingkat kemudahan, keamanan, menyenangkan dan aspek kecerdasan visual spasial. Adapun data yang telah diisi akan ditampilkan sebagai berikut:

Tabel 3

Data Hasil Pedoman Penilaian Uji Kelompok Besar

\begin{tabular}{|c|c|c|c|c|}
\hline No & Nama & Kegiatan 1 & Kegiatan 2 & Kegiatan 3 \\
\hline 1 & Dn & $100 \%$ & $100 \%$ & $100 \%$ \\
\hline 2 & LI & $100 \%$ & $100 \%$ & $100 \%$ \\
\hline 3 & Zd & $100 \%$ & $100 \%$ & $100 \%$ \\
\hline 4 & Ds & $100 \%$ & $100 \%$ & $100 \%$ \\
\hline 5 & Fz & $100 \%$ & $75 \%$ & $100 \%$ \\
\hline 6 & $\mathrm{Rz}$ & $100 \%$ & $75 \%$ & $75 \%$ \\
\hline 7 & $\mathrm{Df}$ & $100 \%$ & $75 \%$ & $100 \%$ \\
\hline 8 & $\mathrm{Rh}$ & $100 \%$ & $75 \%$ & $75 \%$ \\
\hline 9 & $\mathrm{Ib}$ & $100 \%$ & $75 \%$ & $75 \%$ \\
\hline 10 & $\mathrm{Rt}$ & $100 \%$ & $75 \%$ & $75 \%$ \\
\hline 11 & $\mathrm{Gd}$ & $100 \%$ & $75 \%$ & $75 \%$ \\
\hline 12 & $\mathrm{Kk}$ & $100 \%$ & $75 \%$ & $100 \%$ \\
\hline 13 & Ay & $100 \%$ & $75 \%$ & $\mathbf{8 8 , 4 6} \%$ \\
\hline \multicolumn{2}{|r|}{ Rata-rata } & $\mathbf{1 0 0} \%$ & $\mathbf{8 2 , 6 9} \%$ & \\
\hline
\end{tabular}

Berdasarkan hasil tabel di atas dijelaskan bahwa dari ketiga kegiatan untuk mengetahui kecerdasan visual spasial anak di TK Dinden mendapat skor nilai sangat baik yaitu, pada kegiatan 1 dengan rata sebeesar 100\%, kegiatan 2 sebesar 82,69\%, dan kegiatan 3 sebesar 88,46\%. sehingga dapat dikatakan bahwa pengembangan media ini menunjukkan hasil maksimal pada kecerdasan visual spasial anak TK di Dinden. 
Dita Primahasti dkk, Pengembangan media Zliqubo untuk meningkatkan kecerdasan visual spasial anak TK

\section{PEMBAHASAN}

Untuk meningkatkan kecerdasan visual spasial anak secara optimal maka harus diperhatikan kriteria media yang digunakan harus aman, mudah dan menyenangkan sesuai dengan karakteristik anak. Kelayakan produk diperoleh dari data penilaian responden ahli materi, ahli media, ahli desain pembelajaran dan anak sebagai pengguna alat permainan edukatif. Uji kelayakan produk dalam penelitian pengembangan ini dilakukan melalui beberapa tahap uji coba untuk mendapatkan penilaian dan saran agar media yang dikembangkan sesuai dengan perkembangan kecerdasan visual spasial anak. Tahap uji coba kelayakan produk dalam penelitian ini yaitu: 1) tahap validasi ahli materi, 2) tahap validasi ahli media, 3) tahap validasi ahli desain pembelajaran, 4) tahap uji coba kelompok kecil, 4) tahap uji coba besar (kelompok).

Pada tahap uji coba, peneliti melalui 2 dua tahapan yaitu tahap uji coba kelompok kecil dan uji coba kelompok besar. Pada tahap uji coba kelompok kecil, berdasarkan hasil analisis data uji coba kelompok kecil, diperoleh presentase yaitu: (1) $100 \%$ anak dapat melakukan kegiatan I; (2) $80 \%$ anak dapat melakukan kegiatan II; (3) $85 \%$ anak dapat melakukan kegiatan III; (4) $80 \%$ anak mudah melakukan kegiatan; (5) $73,3 \%$ anak aman dalam melakukan kegiatan bermain dengan media Zliqubo (Puzzle Quiet Book); (6) 86,6\% anak merasa senang saat bermain dengan media Zliqubo (Puzzle Quiet Book).

Berdasarkan hasil analisis data uji lapangan kelompok besar, diperoleh presentase yaitu : (1) $100 \%$ anak dapat melakukan kegiatan I; (2) $93,75 \%$ anak dapat melakukan kegiatan II; (3) $87,5 \%$ anak dapat melakukan kegiatan III; (4) 89,7\% anak mudah melakukan kegiatan; (5) $94,86 \%$ anak aman dalam melakukan kegiatan bermain dengan media Zliqubo (Puzzle Quiet Book); (6) 92,30\% anak merasa senang saat bermain dengan media Zliqubo (Puzzle Quiet Book). Berdasarkan analisis data dari hasil uji coba, pada hasil uji coba kelompok kecil, 100\% anak 
dapat memahami warna, 80\% anak dapat memahami bentuk-bentuk geometri, dan 85\% anak dapat memahami bentuk berdasarkan ukuran. Kemudian hasil uji coba kelompok besar, 100\% anak dapat memahami warna, 93,75\% anak dapat memahami bentuk-bentuk geometri, dan $87,5 \%$ anak dapat memahami bentuk berdasarkan ukuran. Dari berbagai uji coba tersebut maka media Zliqubo (Puzzle Quiet Book) dinyatakan "Layak" untuk meningkatkan kecerdasan visual spasial anak. Menurut Yuliani, permainan konstruksi dapat mengoptimalkan perkembangan kecerdasan visual spasial anak. Anak dapat menggunakan alat permainan seperti puzzle (merangkai kepingan gambar), sehingga dengan pengembangan Zliqubo (Puzzle Quiet Book) mampu mengoptimalkan kecerdasan visual spasial anak ${ }^{7}$.

\section{KESIMPULAN}

Berdasarkan hasil dan pembahasan dapat disimpulkan sebagai berikut: 1) Pada setiap penggunaan media dan keefektifan media Zliqubo (Puzzle Quiet Book) untuk meningkatkan kecerdasan visual spasial anak telah memenuhi ketuntasan kelayakan sebesar 100\%, 2) Media Zliqubo (Puzzle Quiet Book) dapat dikatakan efisien pada perkembangan kecerdasan visual spasial anak karena telah memenuhi ketuntasan penilaian dalam hal kemudahan penggunaan sebesar $89,7 \%$, keamanan penggunaaan sebesar $94,86 \%$ dan telah terpenuhi juga ketuntasan penilaian menyenangkan sebesar 92,30\%, dan 3) Media Zliqubo (Puzzle Quiet Book) dapat dikatakan menarik pada perkembangan kecerdasan visual spasial anak karena media Zliqubo (Puzzle Quiet Book) mengajarkan secara menarik komponen kecerdasan visual spasial (warna, bentuk geometri, ukuran, arah) dalam satu media dengan presentase 100\% anak dapat melakukan kegiatan I (memahami warna);93,75\% anak dapat melakukan kegiatan II (memahami bentuk-

7 Yuliani. 2012. Bermain Kreatif Berbasis Kecerdasan Majemuk. Jakarta: Indeks.,h. 190 
Dita Primahasti dkk, Pengembangan media Zliqubo untuk meningkatkan kecerdasan visual spasial anak TK

bentuk geometri); dan 87,5\% anak dapat melakukan kegiatan III (memahami benda berdasarkan ukuran).

\section{DAFTAR PUSTAKA}

Ali. 2012. Penelitian Pendidikan, Prosedur dan Strategi Mengajar. Bandung: Aksara.

Anas Sudijono. 2006. Pengantar Statistik Pendidikan. Jakarta: Raja Grafindo Persada.

Ardhana. 2010. Konsep Penelitian Pengembangan dalam Bidang Pendidikan dan Pembelajaran. Malang: Universitas Negeri Malang.

Busthomi. 2012. Panduan Lengkap PAUD Melejitkan Potensi dan Kecerdaan Anak Usia Dini.Jakarta : Citra Publishing.

Eliyawati Cucu. 2005. Pemilihan dan Pengembangan Sumber Belajar untuk Anak Usia Dini. Jakarta. Depdiknas.

Eko Putro Widoyoko. 2012. Teknik Penyusunan Instrumen Penelitian. Yogyakarta : Pustaka Pelajar.

Gardner, Howard. 2003. Kecerdasan Majemuk. (Terjemahan Drs. Alexander Sindoro). Batam Centre : Interaksara.

Gardner, Howard. 2013. Multiple Intelligences. Tangerang Selatan: Interaksara

Gagne. 2007. Media Pendidikan. Jakarta : PT Raja Grafindo Persada.

Hartati, Sofia. 2005. Perkembangan Belajar Pada Anak Usia Dini. Jakarta: Departemen Pendidikan Nasional.

Indriana, Dina. 2011. Ragam Alat Bantu Media Pengajaran. Jogjakarta : Diva Perss.

Jamaris. 2006. Perkembangan Anak. Jakarta: Erlangga.

Mulyasa. 2012. Manajemen PAUD. Bandung: Remaja rosdakarya.

Musfiroh. 2008. Pengembangan Kecerdasan Majemuk. Jakarta :Gracindo.

Sukmadinata. 2009. Metode Penelitian Pendidikan. Bandung: Remaja Rosdakarya Bandung.

Sudjana, Ibrahim. 2010. Penelitian dan Penilaian Pendidikan. Bandung : Sinar Baru Algesindo. 
Suyanto, Slamet. 2005. Pembelajaran untuk Anak Taman Kanak-Kanak. Yogyakarta: UNY Press.

Yulianti, Rani. 2008. Permainan yang Meningkatkan Kecerdasan Anak. Jakarta: Laskar Askara.

Yuliani. 2012. Bermain Kreatif Berbasis Kecerdasan Majemuk. Jakarta: Indeks.

Yuniarti. 2014. Asuhan Tumbuh Kembang. Bandung: PT Refika Aditama. 